\title{
Erratum to: On Volterra Three-Point Problems for the Sturm-Liouville Operator Related to Potential Symmetry
}

\author{
S. A. Jumabayev ${ }^{* *}$ and D. B. Nurakhmetov ${ }^{2 * *}$ \\ ${ }^{1}$ Academy of Public Administration under the President of the Republic of Kazakhstan, \\ Astana, 010000 Kazakhstan \\ ${ }^{2}$ Saken Seifullin Kazakh Agrotechnical University, 010011 Kazakhstan \\ Received November 19, 2018
}

DOI: $10.1134 / \mathrm{S} 000143461811041 \mathrm{X}$

The original article can be found online at https://doi .org/10.1134/S0001434618090274.

In the text of our article, the following correction must be made: the name of the first author should be changed from S. A. Jumabaev to S. A. Jumabayev.

\footnotetext{
${ }^{*}$ E-mail: ser \_jum@inbox.ru

${ }^{* *}$ E-mail: dauletkaznu@gmail.com
} 